\title{
A Japanese pitch accent practice program and L1 influence on pitch accent acquisition
}

\author{
Jeff Peterson*
}

\begin{abstract}
Recent research has demonstrated that learners of Japanese struggle producing correct Japanese pitch accent. The goal of the present study was to investigate the effect learners' first language (L1) may have on accent acquisition following the introduction and use of a digital Japanese Pitch Accent Learning and Practice (PALP) program in two Japanese courses. The PALP program visually and aurally presents learners with pitch patterns and requires them to select the correct pitch accent pattern for new vocabulary. Participants' pitch accent abilities were assessed at the beginning and end of their courses. A mixed design ANOVA was conducted to analyze the effect of learners' L1 on pitch accent acquisition. Results evince a significant interaction effect between participant group (treatment/control) and L1 (Chinese/English), $F(1,24)=10.09, p<.01\left(\eta^{2}=.30\right)$. Specifically, English L1 participants in the treatment group considerably outperformed the control group English L1 participants. However, the Chinese L1 participants in both groups performed at approximately equal levels. These results suggest the existence of an L1 influence on pitch accent acquisition.
\end{abstract}

Keywords. Japanese, pitch accent, L1 influence, transfer, CALL

1. Introduction. Students of Japanese often face many difficulties in their attempts to gain control of standardized Japanese pronunciation. Many struggle distinguishing between and mastering double-mora phonemes (i.e., long and short vowel sounds), especially at the lower level (Deguchi 2011, Kawai \& Hirose 2000). Others have difficulty producing correct intonation in Japanese (Abe 1957, Beckman \& Pierrehumbert 1986, Eda 2004, Venditti \& Swerts 1996). Furthermore, other leaners may struggle with parts of Japanese speech that they may not even know exist (Venditti \& Swerts 1996). For example, many (possibly unbeknownst to themselves) struggle producing correct Japanese pitch accent (A \& Hayashi 2010, Cutler \& Otake 1999, Hirose 2004, Nakamura et al. 2013). Nakamura et al. (2013) state that many learners of Japanese don't know that Japanese has pitch accent because it is "rarely taught in [the] classroom" (:2554)

In contrast to English, Japanese uses length of vowels to distinguish meaning in similar words. Thus, in classrooms where Japanese is taught, teachers often cover the difference in long and short vowel sounds. Because the meanings of words in Japanese change depending on the length of the vowel this is often seen as an important area of study within the classroom. For example, with the short vowel/i/, the Japanese word biru means building. However, when the same vowel /i/ is pronounced as a long vowel, the word biru changes to biiru and the meaning changes from building to beer. One can imagine the difficulty students may have when they wish to communicate the word for beer and instead use the word for building.

Issues with differentiating between long and short vowels can be one of the most difficult tasks beginning learners have with Japanese pronunciation. However, one issue in Japanese pronunciation that affects both beginners and advanced learners is Japanese pitch accent. Because there is an eclectic mix of problems learners have with Japanese pitch accent, a deeper

\footnotetext{
*Author: Jeff Peterson, Purdue University (petersonj@purdue.edu)
} 
understanding of Japanese pitch accent and how it is being taught is required to ameliorate the difficulty many learners of Japanese face.

\section{Review of Literature.}

2.1. JAPANESE PITCH ACCENT. A distinction between English and Japanese is their use of pitch accent. The use of pitch accent indicates the use of different pitches in words and phrases to distinguish between the different meanings of said words and phrases. A form of pitch accent is used in many languages. Chinese, for example, uses what many call tones, or different pitch sound sequences to distinguish between different words. In this sense, Japanese accentuation is more similar to Chinese than to English. In contrast with Chinese, however, standard Japanese is more limited and takes advantage of strictly high and low pitch sounds to make distinctions between certain words. The combination and order of these high and low pitch sounds are easily recognized by native Japanese speakers and make up the differences in the meanings of words like oyster and persimmon (both of which are realized as /kaki/).

Because there are no set rules to know whether a word in Japanese starts with a high pitch and drops to a lower pitch or if the opposite is true, even those non-native speakers of Japanese who are aware of Japanese pitch accent are often left to inquire of a native speaker or instructor what the pitch pattern of certain words are. Many instructors, not being pitch accent experts themselves, are often unable to answer how to pronounce the pitch accent of words correctly without further inquiry. Some instructors may not even know themselves that pitch accent exists in Japanese. In the past, but less in recent years, students of Japanese were often taught that Japanese is what some call a 'flat language'. Those who taught this claimed that Japanese is a language with no pitch or tonal accent (Warnick 2014). This is an oversimplification and incorrect as shown in Cutler and Otake's (1999) research. Cutler and Otake found that native Japanese speakers were able to identify differences in meaning based on pitch accent $74 \%$ of the time. Despite such findings, in recent years very little has been done in the classroom to help students learn Japanese pitch accent (Kawai \& Hirose 2000; Venditti \& Swerts 1996). Learners of Japanese who lack the ability to distinguish differences in pitch may find themselves misunderstanding others and others misunderstanding them.

For example, the pitch accent for the words bridge, edge, and chopsticks in Japanese are different. However, when these three words are written out in three of the four alphabets that exist in Japanese they are all written in such a way that each meaning is indistinguishable; i.e., all three are realized as /hashi/. Even experienced learners of Japanese often face difficulties with this subtle difference. When the word hashi is pronounced beginning with a high pitch on the first mora and then lowers on the second, the word means chopsticks. When starting with a low pitch followed by a high pitch, the word can mean either bridge or edge. If, however, a particle such as $g a$ is added, the pitch on $g a$ is low for the word meaning bridge, and remains high for the word meaning edge.

With such a subtle difference, many learners of Japanese find it difficult to distinguish between these types of words. Now, one may conclude that this difference is trivial because of the amount of context one is given in conversations. For example, the meanings that the word hashi has are not likely to be mixed up based on context. However, a final example of this difference in meaning based on pitch accent includes the words "sometime" and "the 5th of the month," which are both realized as /itsuka/. This may be one of the most difficult differences among these words because both meanings relate to time. Clearly even the context won't give 
one the full meaning of the word to be said when both words deal with points in time. Without knowing the words' correct pitch patterns, confusion may occur and further elaboration and explanation of the situation would be required for the interlocutor to understand which meaning is to be conveyed.

2.2. L1 INFLUENCE ON PRONUNCIATION. As discussed above, Japanese pitch patterning in pronunciation is more similar to Chinese tonal pronunciation than English stress accent. Intuition may tell us that due to the similarities in Japanese pitch accent and Chinese pronunciation, Chinese L1 learners of Japanese may be more successful in recognizing and acquiring Japanese pitch accent. However, research suggests that the more similar the target language (TL) sounds are to L1 sounds, the more difficult they are to acquire (Flege 1995, Wode 1983).

The reason seems to be that ... the larger the differences are, the more easily they tend to be noticed; therefore, learning is more likely to take place. In contrast, minimal differences often go unnoticed, resulting in non-learning. (Major 2008:72)

These findings would suggest that it may be more difficult for Chinese learners of Japanese to acquire pitch accent because of the similarities it has with their L1. However, Major (2008) further notes that differing experimental conditions can produce different results. The current study will show more clearly the influence of learners' L1 on Japanese pronunciation following focused practice of Japanese pitch accent using a new Pitch Accent Learning and Practice (PALP) Program which will be discussed later.

2.3. ISSUES IN TEACHING JAPANESE PITCH ACCENT. Even when contextualization helps express meaning, many learners of Japanese are often mimicked or mocked for their poor pronunciation (Derwing \& Munro 2005, Kawai \& Hirose 2000). This may be a problem due to a lack of classroom time being devoted to the teaching of Japanese pronunciation.

The lack of materials and time teaching pitch accent is shocking and effective teaching/learning materials are not prevalent (Kawai \& Hirose 2000, Venditti \& Swerts 1996). Most learners of Japanese lack the skills to perform at a near native speaking level (when it comes to pronunciation) and "most teachers receive no training in pronunciation teaching" (Kawai \& Hirose 2000:132, Mizutani 1993, Taniguchi 1991). Nakamura et al. (2013) continues by stating that a large number of "native teachers of Japanese . . are not good at pitch labeling" (:2554). This and the fact that the four Japanese writing systems (kanji, hiragana, katakana, and rōmaji) "do not require writers to mark the pitch attribute visually" hinders learners' ability to correctly pronounce words in Japanese (Nakamura et al. 2013:2554).

2.4. JAPANESE PitCH ACCENT TEACHING MATERIALS. In an effort to bolster the obvious lack in pitch accent teaching and learning materials, Another system to enhance the abilities of learners' accents was created in 2004 by Keikichi Hirose. Hirose created a system where students were able to find out where and how they were mispronouncing words in Japanese. Hirose found that participants in their study of the system were able to obtain a better idea of their pronunciation problems through the system. They also found that adding visuals to the feedback helped participants understand more quickly what the correct pronunciation was. This indicates that after being taught and given feedback, learners are able to learn and produce correct Japanese pitch accent.

2.5. PITCH ACCENT TRAINING AND PRACTICE. Other attempts at helping students' accent have been fruitful. A and Hayashi (2010) had 15 Mongolian and Chinese learners of Japanese use a 
learning technique called shadowing. In shadowing they would repeat after a given text spoken by a native speaker. To find out if the difference of effectiveness of shadowing depended on the learners' proficiency level, the research participants were divided into two groups according to their level of Japanese proficiency. The participants shadowed a dialog ten times during three sessions without seeing a script over a seven-week period. The researchers found that the speech rate and accuracy of pitch accent rose significantly after seven weeks in both groups. Again this seems to suggest that learners regardless of proficiency level can increase their Japanese pitch accent accuracy over time through practice.

2.6. SUMMARY. Japanese pitch accent can be very difficult for learners of Japanese to master. This difficulty creates a barrier for many students, blocking them from smooth communication with native speakers and may even lead to students being mocked or avoided. Moreover, many instructors of Japanese lack the abilities and the teaching materials needed to help their students acquire the skills to correctly produce and perceive the differences between words with differing pitch accents. Furthermore, research shows that learners whose L1 is more similar to the TL struggle more in acquiring correct TL pronunciation.

To help offset these weaknesses in the teaching and learning of Japanese pitch accent some research has been conducted. The research that has been done has shown promise in the effect of teaching and learning Japanese pitch accent. However, because of the small amount that has been done in this area, further study of teaching using different methods and training would be beneficial to the field and broaden our knowledge of the effects of these types of training methods. The current study is part of a larger study, seeking to fill these gaps by further exploring pitch accent instruction and learning through technological systems.

\subsection{RESEARCH QUESTION.}

Is there a relationship between learners' L1 and their ability to learn correct Japanese pitch accent?

\section{Methodology.}

3.1. PARTICIPANTS. Participants in this study included 28 novice level (first semester) Japanese as a Foreign Language (JFL) learners from a large mid-western university in the U.S. Twenty-seven participants' ages ranged from 18 to 22 . One participant reported being over 24 . The participants' male-to-female ratio was 21:7. Furthermore, two L1s were represented. Sixteen participants' L1 was Chinese, and twelve were English. Furthermore, 22 participants identified themselves as Asian, 2 as Black, and 4 as White. Of those that identified as Asian, 18 identified as being Chinese.

Participants were chosen based on the course they were enrolled in (online) and the willingness of the treatment group's course instructor to allow the use of the new pitch accent learning materials (PALP program) in their course. Participants were all enrolled in a firstsemester, novice Japanese online course. At the time of the study all participants had studied two Japanese syllabaries (i.e., hiragana and katakana) and were expected to be able to read and write basic Japanese using both sets of characters.

Participants were separated into two groups, a treatment group and a control group. The treatment and control groups had 20 and 8 participants respectively. The treatment group was required to use the PALP program as part of their study of Japanese pitch accent and vocabulary. The control group used a traditional method for studying Japanese pitch accent and vocabulary. 
Traditional method is operationalized here as the use of the Nakama 1 textbook and other online materials commonly used in novice level Japanese courses.

3.2. THE PALP PROGRAM. The researcher designed a new technological system for the teaching and learning of Japanese pitch accent; i.e., the Pitch Accent Learning and Practice (PALP) program. (Final computer programing of the software was completed by Purdue University's Dr. Kazumi Hatasa.)

The PALP program is a computer-based program consisting of two main modules: an input module, and a practice module. (Participants were able to output or practice pronouncing vocabulary items on a separate web application called Speak Everywhere (see: Fukada, 2013). Speak Everywhere, created at Purdue University by Dr. Atsushi Fukada, is often used in speaking practice and speaking tests outside the classroom.) During the input module phase of the PALP program, leaners are introduced to new vocabulary words (see Figure 1). Learners are shown the vocabulary written in Japanese as well as the English translation and a visual depiction of the target vocabulary's pitch pattern. During this phase, an audio clip of the vocabulary is played automatically.

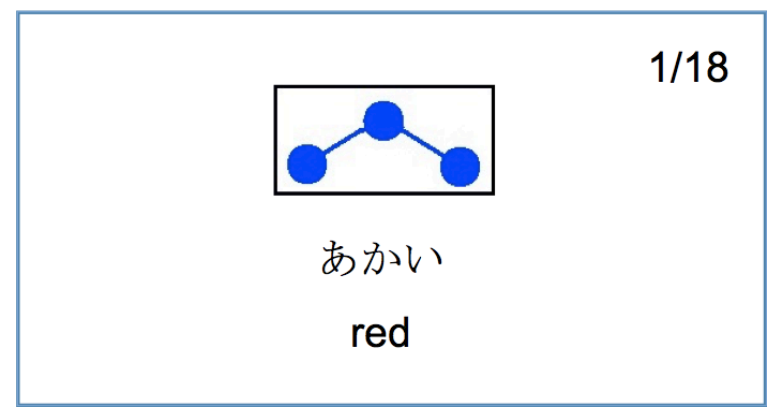

Figure 1. Vocabulary item introduced with depiction of pitch pattern, English translation, and model audio.

Following the initial visual depiction and vocabulary input, a new screen appears with identical information but with multiple options for the pitch pattern (see Figure 2). Leaners then use the computer mouse to choose which pitch pattern is correct for the target vocabulary. The audio is not replayed on this screen until the leaner selects which pitch pattern they believe correlates with the target vocabulary. If the learner answers correctly, the audio plays and the next vocabulary item is shown. If they answer incorrectly, they are kept on the screen until they choose the correct pitch pattern. Furthermore, when a vocabulary item is answered incorrectly, it is added to the end of the vocabulary list to be reviewed again in the same practice session (see Figure 3).

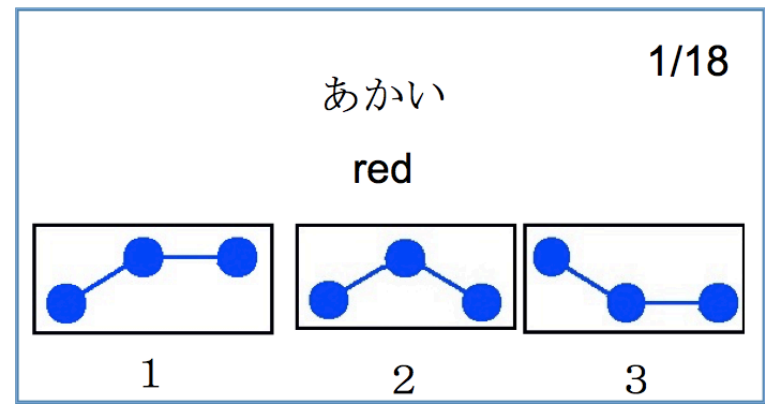

Figure 2. Learner selects which pitch pattern correlates with the target vocabulary. 


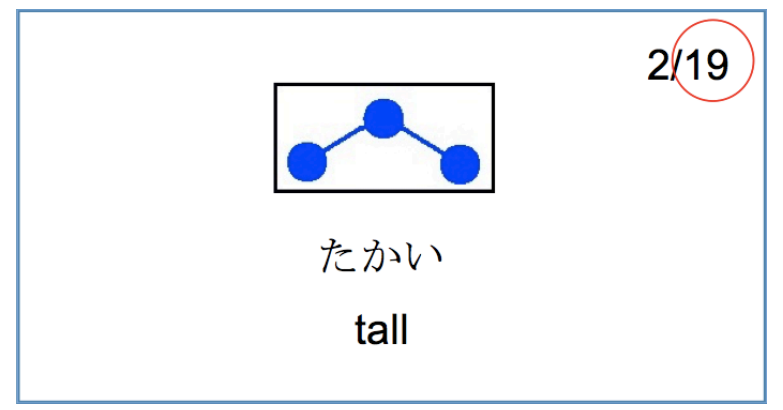

Figure 3. Incorrectly answered item added to end of list for further review.

The second phase is made up of a practice module. This module is used to check the learners' knowledge of the accent patterns and the meaning of the target vocabulary through a multiple choice question similar to what occurs on the second screen shown during phase 1 (see Figure 2). Here, the audio is, again, played only after the learner has selected an answer (see Figure 4). In the same manner as the input module, vocabulary items that are answered incorrectly are added to the end of the list to be practiced again.

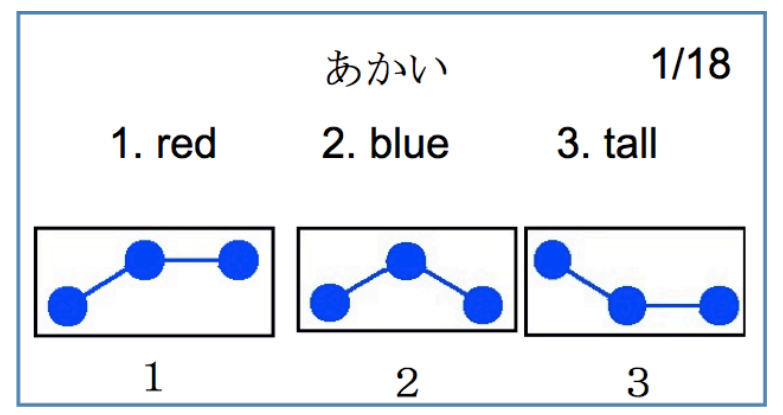

Figure 4. Practice module

3.3. Procedures AND TREATMENTS. Participants in the treatment group were introduced to the PALP program at the beginning of their first-semester Japanese course. They were given instructions on how to use the program outside of class. Participants were then required to use the program to practice pronunciation throughout the semester. They also used Speak Everywhere to practice pronouncing the vocabulary words introduced in the PALP program. (The control group also used Speak Everywhere as part of their coursework.) Participants received course credit for completing each chapter's vocabulary practice using the PALP program. After finishing each module, participants would take a picture of the final screen of the program and turn the picture into their instructor to receive credit. The PALP program introduced vocabulary items that all first-semester students learn while studying chapters 3-5 of the Nakama 1 textbook.

In order to test the efficacy of the new technological system for teaching and learning Japanese pitch accent, participants were recorded reading aloud 20 vocabulary items selected from the list of vocabulary that students would have practiced while studying chapters 3-5 in their Nakama 1 textbooks. Participants completed these recordings in person at the researchers office as part of pre-, post-, and delayed post-tests (three assessments). (Due to the nature of online courses, four participants in the control group were unable to meet in person for the pretest only, and completed the pre-test recordings during online, one-on-one synchronous meetings, rather than in person.) The vocabulary items on the assessments were presented to the 
participants in the format shown in Figure 5. The pre-test was completed at the beginning of the semester prior to any instruction of vocabulary introduced in Nakama 1 chapters 3-5. Participants completed the post-test following completion of chapter 5 in Nakama 1. The treatment group completed the delayed post-test two weeks later. Due to time limitations, the control group completed the delayed post-test one week following the post-test.
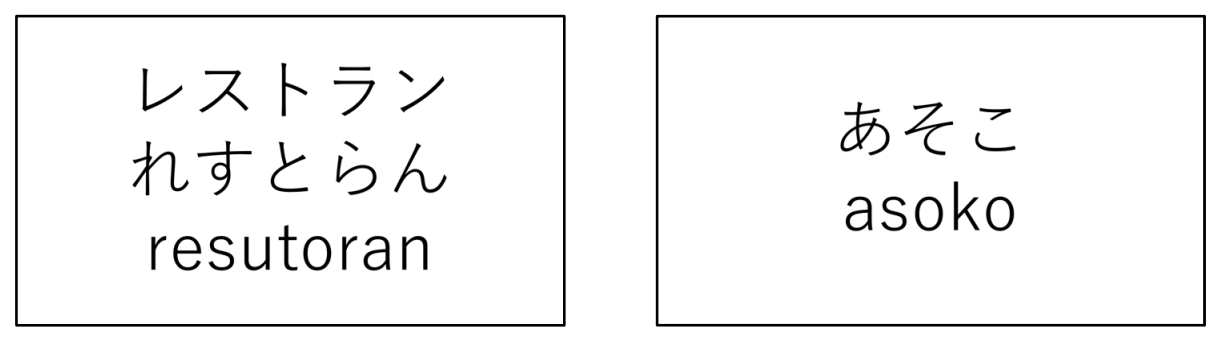

Figure 5. Examples from assessments

3.4. ANALYSIS. Following testing (pre-, post-, delayed post-tests), two raters (a native speaker and a near-native speaker holding a Superior level certification on the ACTFL OPI) graded the data (recordings) according to pitch accent accuracy. Each word was awarded one point if the participant pronounced the word with the correct pitch pattern. When the two raters' scores did not match, a third (native speaker) rater graded the recorded word. The word was then rated correct or incorrect based on which two of the raters' scores matched. The researchers then ran descriptive and inferential statistics on the collected data. To answer the research question presented here, the researcher conducted a mixed design analysis of variance (ANOVA).

\section{Results.}

4.1. RESEARCH QUESTION. Is there a relationship between learners' L1 and their ability to learn correct Japanese pitch accent?

The researcher addressed this question by analyzing the data collected from the assessment recordings in both the treatment and control groups as described previously. The researcher analyzed the data using descriptive analyses as well by conducting a mixed design ANOVA.

4.2. DESCRIPTIVE DATA. The dependent variables considered here are the pre-, post-, and delayed post-test scores. Scores on these assessments were based on the accuracy of the pitch accent pattern participants produced while reading aloud each of the 20 words shown to them during each test. Tables 1, 2, and 3 show the descriptive statistics summary of participants' test scores as a function of group and L1. 
Group/L1

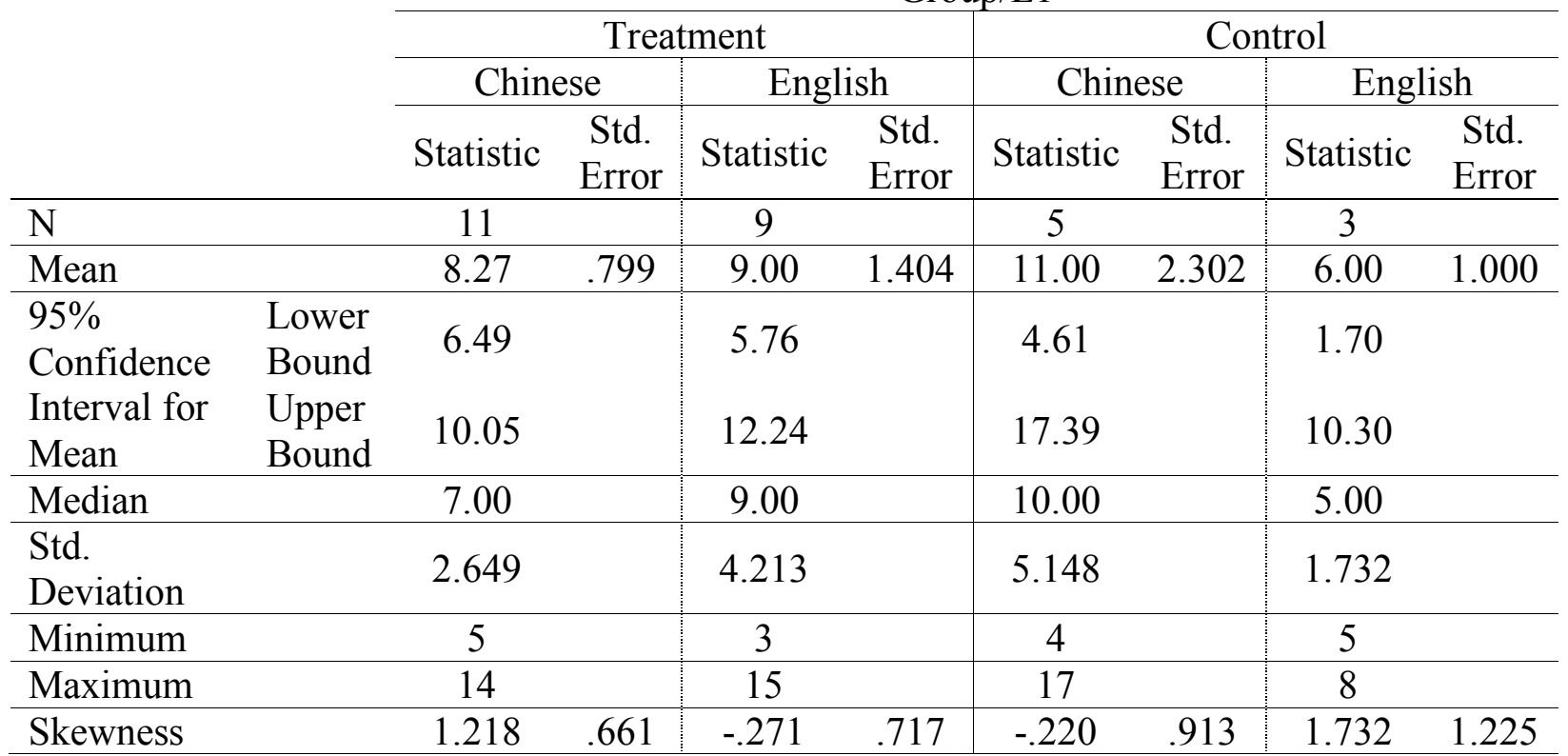

Table 1. Descriptive Statistics - Pre-test Scores by Group and L1

Group/L1

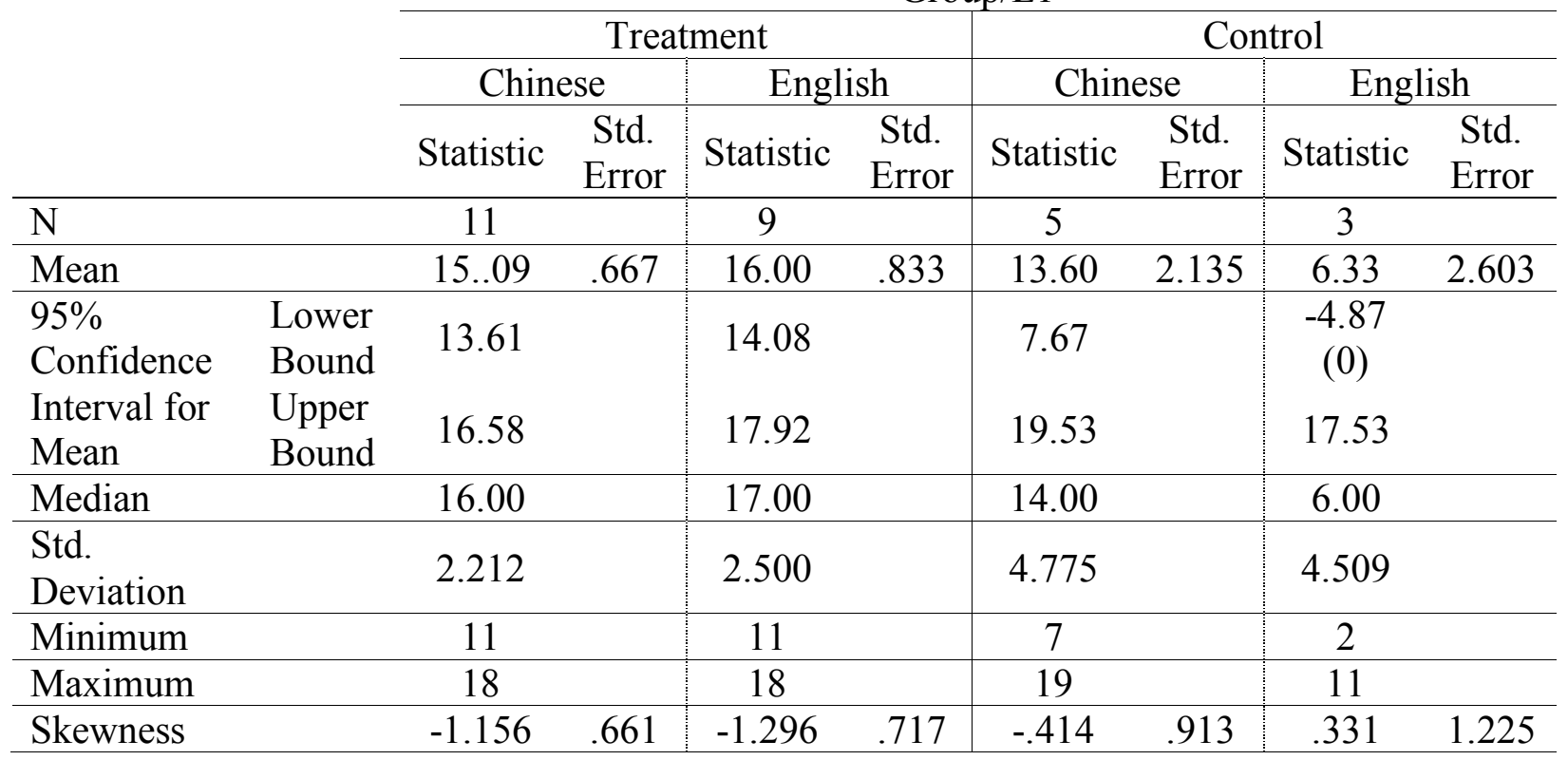

Table 2. Descriptive Statistics - Post-test Scores by Group and L1 
Group/L1

\begin{tabular}{|c|c|c|c|c|c|c|c|c|c|}
\hline & \multirow{2}{*}{\multicolumn{4}{|c|}{ Treatment }} & \multirow{2}{*}{\multicolumn{4}{|c|}{ Control }} \\
\hline & & & & & & & & & \\
\hline & & \multicolumn{2}{|c|}{ Chinese } & \multicolumn{2}{|c|}{ English } & \multicolumn{2}{|c|}{ Chinese } & \multicolumn{2}{|c|}{ English } \\
\hline & & Statistic & $\begin{array}{l}\text { Std. } \\
\text { Error }\end{array}$ & Statistic & $\begin{array}{l}\text { Std. } \\
\text { Error }\end{array}$ & Statistic & $\begin{array}{l}\text { Std. } \\
\text { Error }\end{array}$ & Statistic & $\begin{array}{l}\text { Std. } \\
\text { Error }\end{array}$ \\
\hline $\mathrm{N}$ & & 11 & & 9 & & 5 & & 3 & \\
\hline Mean & & 12.27 & .715 & 13.56 & 1.168 & 13.00 & 2.608 & 4.67 & 1.453 \\
\hline $\begin{array}{l}95 \% \\
\text { Confidence }\end{array}$ & $\begin{array}{l}\text { Lower } \\
\text { Bound }\end{array}$ & 10.68 & & 10.86 & & 5.76 & & $\begin{array}{c}-1.58 \\
(0)\end{array}$ & \\
\hline $\begin{array}{l}\text { Interval for } \\
\text { Mean }\end{array}$ & $\begin{array}{l}\text { Upper } \\
\text { Bound }\end{array}$ & 13.87 & & 16.25 & & $\begin{array}{c}20.24 \\
(20)\end{array}$ & & 10.92 & \\
\hline Median & & 12.00 & & 13.00 & & 14.00 & & 5.00 & \\
\hline $\begin{array}{l}\text { Std. } \\
\text { Deviation }\end{array}$ & & 2.370 & & 3.504 & & 5.831 & & 2.517 & \\
\hline Minimum & & 8 & & 9 & & 6 & & 2 & \\
\hline Maximum & & 16 & & 19 & & 19 & & 7 & \\
\hline Skewness & & -.121 & .661 & .388 & .717 & -.265 & .913 & -.586 & 1.225 \\
\hline
\end{tabular}

Table 3. Descriptive Statistics - Delayed Post-test Scores by Group and L1

4.3. HYPOTHESIS TEST ASSUMPTIONS FOR ANOVA. In conducting the mixed design ANOVA, three assumptions were completely maintained; 1) independence, 2) homogeneity of covariance matrices, and 3) sphericity of the covariance matrix. The assumption of normality was all but fully sustained, due to an exiguous degree of skewness of the treatment group post-test score distributions for both the Chinese and English L1 participants, as well as the control group pretest score distribution for English L1 participants. The assumption of homogeneity of variance was also all but fully met, due to slightly unequal variance in delayed post-test scores.

4.4. INFERENTIAL DATA. Tables 4, and 5 summarize the results of the mixed design ANOVA for the test scores. Figure 6 also shows the interaction between participant group and L1. These results show that the time * group $* \mathrm{~L} 1$ interaction was not significant, $F(2,48)=.97, p>.05$.

\begin{tabular}{lrcrcc} 
Source & Type III Sum of Squares & df & Mean Square & $F$ & $p$ \\
\hline Time * Group * L1 & 10.513 & 2 & 5.257 & .965 & .388 \\
Error (Time) & 261.372 & 48 & 5.445 & & \\
\hline
\end{tabular}

Table 4. Results of Mixed Design ANOVA - Tests of Within-Subjects Effects

\begin{tabular}{lrcrccc} 
Source & Type III Sum of Squares & df & Mean Square & $F$ & $p$ & $\eta^{2}$ \\
\hline Group * L1 & 83.581 & 1 & 83.581 & 10.086 & $\mathbf{. 0 0 4}^{*}$ & .296 \\
Error & 198.885 & 24 & 8.287 & & & \\
\hline
\end{tabular}

*. Statistical Significance

Table 5. Results of Mixed Design ANOVA - Tests of Between-Subjects Effects

However, these results do show a significant interaction effect between participants' group and L1, $F(1,24)=10.09, p<.01\left(\eta^{2}=.30\right)$. To break down this interaction, estimated marginal means were calculated comparing each L1 across treatment and control group participants. Table 6 summarizes these data. 


\begin{tabular}{llrrrr} 
& & & \multicolumn{3}{c}{$95 \%$ Confidence Interval } \\
Group & L1 & Mean & Std. Error & Lower Bound & Upper Bound \\
\hline \multirow{2}{*}{ Treatment } & Chinese & 11.879 & .868 & 10.087 & 13.670 \\
& English & 12.852 & .960 & 10.871 & 14.832 \\
\multirow{2}{*}{ Control } & Chinese & 12.533 & 1.287 & 9.876 & 15.190 \\
& English & 5.667 & 1.662 & 2.236 & 9.097 \\
\hline
\end{tabular}

Table 6. Estimated Marginal Means for Group * L1 Interaction

Figure 6 further illustrates this interaction.

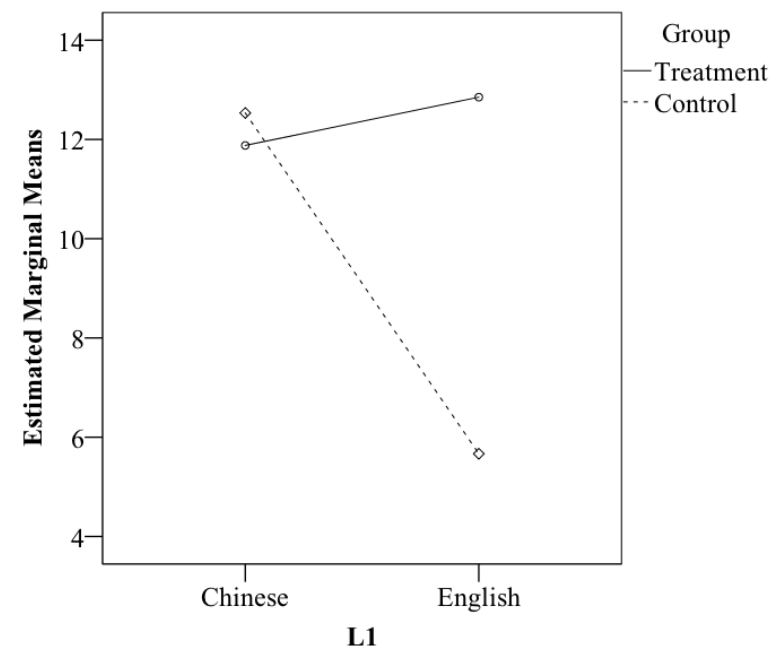

Figure 6. Group * L1 Interaction Graph

5. Discussion. Results of the mixed design ANOVA evince a significant interaction effect between participants' group and L1, $F(1,24)=10.09, p<.01\left(\eta^{2}=.30\right)$. This indicates that the scores in the treatment and control groups differed based on participant L1. Table 6 further shows that although the Chinese L1 participants' pitch accent performances were very similar across groups, the English L1 participants in the treatment group considerably outperformed the control group English L1 participants. Moreover, the treatment group English L1 participants performed at approximately the same level as the Chinese L1 participants. Although both Chinese and English L1 participant scores differed across groups, the difference is far more pronounced between English L1 participants (see Figure 6), suggesting that English L1 participants' test scores were more influenced by the treatment than Chinese L1 participants. Given these results, we reject the null hypothesis, thus suggesting that learners' L1 does have an effect on their ability to learn Japanese pitch accent. In other words, these results suggest that without any specific pitch accent training intervention, learners whose L1 pronunciation type is more similar to Japanese (Chinese L1) are more able to acquire correct Japanese pitch accent than those whose L1 pronunciation type is less similar to Japanese (English L1). The results of the ANOVA also indicate that this interaction is practically significant (i.e., meaningful), producing a large effect size, $\eta^{2}>.26$.

These results, however, are contrary to those found by Flege (1995), Major (2008), and Wode (1983). Results of their studies suggest that greater L1 departure from the TL produces more salient differences between the L1 and the TL and thus more learning. However, the 
current study's results suggest that the Chinese L1 learners appear to acquire Japanese pitch accent better than their English L1 counterparts who did not use the PALP program, despite the Japanese pitch system being more similar to the Chinese tonal system than to the English stress system. The differences between Japanese and English accent seem to not have been salient enough to result in control group English L1 learners noticing differences, and thus lead to L1 transfer.

5.1. PedagogiCAl IMPLiCATIONS AND RECOMMENDATIONS. Results of this study suggest that, if given training and practice, English L1 learners can learn and produce correct Japanese pitch accent. Table 6 shows that treatment group English L1 participants performed at approximately the same level as the Chinese L1 participants. This is a promising result, further bolstering the results of A and Hayashi (2010) and Hirose (2004), indicating that with concentrated practice, Japanese language learners can acquire correct pitch accent. Given these results the author would recommend further implementation of pitch accent learning and practice programs in Japanese language courses, in particular for courses that include English L1 learners.

5.2 LIMITATIONS AND FUTURE SUGGESTIONS. This study included a range of participants from three online first-semester Japanese courses. The nature of these online courses reduced the researcher's ability to procure a large number of participants. Furthermore, as participants selfenrolled in the courses, the author was unable to conduct random sampling as part of this study.

Further replication studies, including data from additional online courses, will further offset the above mentioned limitations and strengthen the implications of this study.

Furthermore, studies using a system similar to the PALP program within a traditional course would also indicate the effect of concentrated pitch accent training for traditional students.

6. Conclusion. This study has attempted to answer the following key question. Is there a relationship between learners' L1 and their ability to learn correct Japanese pitch accent? The present study found that if given no specific pitch accent training intervention beyond what is traditionally available, learners whose L1 pronunciation type is more similar to Japanese (Chinese L1) are more able to acquire correct Japanese pitch accent than those whose L1 pronunciation type is less similar to Japanese (English L1). This suggests that there is a relationship between learners' L1 and their ability to learn correct Japanese pitch accent. This adds contrasting results to what has been found previously (see Major, 2008).

Although results suggest an interaction between learner L1 and the type of pitch accent instruction they received, further replication studies in different contexts using similar programs are needed to further strengthen these findings.

Given these results, it is hoped that instructors of Japanese will begin (or continue) implementing programs that assist learners in continual, concentrated practice of Japanese pitch accent. Moreover, these results indicate that these practice programs are particularly necessary for English L1 learners of Japanese.

\section{References}

A, R., \& Hayashi, R. 2010. The effect of shadowing training for Mongolian and Chinese learners of Japanese. IEICE Technical Report, 109(451), 19-24.

Abe, I. 1957. On Japanese intonation: An experiment. Lingua, 7, 183-194.

https://doi.org/10.1016/0024-3841(57)90081-5 
Beckman, M. E., \& Pierrehumbert, J. B. 1986. Intonational structure in Japanese and English. Phonology, 3(01), 255-309.

Cutler, A., \& Otake, T. 1999. Pitch accent in spoken-word recognition in Japanese. The Journal of the Acoustical Society of America, 105(3), 1877-1888.

Deguchi, M. 2011. The Role of Foot Structure in Teaching Vowel Length Distinctions in Japanese. Theory and Practice in Language Studies, 1(6).

https://doi.org/10.4304/tpls.1.6.567-571

Derwing, T. M., \& Munro, M. J. 2005. Second language accent and pronunciation teaching: A research-based approach. Tesol Quarterly, 39(3), 379-397.

Eda, S. 2004. Processing of intonation patterns in Japanese: Implications for Japanese as a foreign language (Doctoral dissertation). The Ohio State University. Retrieved from http://rave.ohiolink.edu/etdc/view?acc num $=$ osu1086187589

Flege, J. E. 1995. Second language speech learning: Theory, findings, and problems. In W. Strange (Ed.), Speech perception and linguistic experience: Issues in cross-linguistic research (pp. 233-277). Timonium, MD: York Press.

Fukada, A. 2013. An online oral practice/assessment platform: Speak Everywhere. The IALLT Journal, 43(1), 64-77.

Hirose, K. 2004. Accent type recognition of Japanese using perceived mora pitch values and its use for pronunciation training system. In International Symposium on Tonal Aspects of Languages: With Emphasis on Tone Languages (pp. 77-80). Beijing, China. Retrieved from http://www.isca-speech.org/archive open/tal2004/tal4 077.html

Kawai, G., \& Hirose, K. 2000. Teaching the pronunciation of Japanese double-mora phonemes using speech recognition technology. Speech Communication, 30(2-3), 131-143. https://doi.org/10.1016/S0167-6393(99)00041-2

Major, R. C. 2008. Transfer in second language phonology. In J. G. H. Edwards \& M. L. Zampini (Eds.), Phonology and second language acquisition (Vol. 36, pp. 63-94). John Benjamins.

Mizutani, O. 1993. Executive Summary. In Japanese Speech and Japanese Education (pp. 1-4). Tokyo, Japan: Ministry of Education.

Nakamura, I., Minematsu, N., Suzuki, M., Hirano, H., Nakagawa, C., Nakamura, N., ... Hashimoto, H. 2013. Development of a web framework for teaching and learning Japanese prosody: OJAD (online Japanese accent dictionary). In INTERSPEECH (pp. 2554-2558). Retrieved from http://pallas.gavo.t.utokyo.ac.jp/ mine/paper/PDF/2013/INTERSPEECH_p2554-2558_t2013-8.PDF

Taniguchi, H. 1991. Results of a survey on Japanese pronunciation teaching. Prosody and Its Role in TJSL. Ministry of Education, Tokyo, 17-21.

Venditti, J. J., \& Swerts, M. 1996. Intonational cues to discourse structure in Japanese. In Proceedings of the Fourth International Conference on Spoken Language (Vol. 2, pp. 725-728). IEEE. Retrieved from http://ieeexplore.ieee.org/abstract/document/607464/

Warnick, J. P. 2014. [Personal communication].

Wode, H. 1983. Phonology in L2 acquisition. In H. Wode (Ed.), Papers on language acquisition, language learning and language teaching (pp. 175-187). Heidelberg, Germany: Groos. 